\title{
Avaliação de desinfetantes de superfície utilizados em Odontologia
}

\section{Evaluation of surface disinfectants utilized in dentistry}

\author{
Célia Regina Gonçalves e Silva* \\ Antonio Olavo Cardoso Jorge**
}

\begin{abstract}
RESUMO: Desinfecção de superficie é um procedimento realizado nas áreas externas do equipamento odontológico e demais itens do consultório. O objetivo deste trabalho foi analisar a ação de quatro desinfetantes utilizados em Odontologia: álcool etílico a $77^{\circ} \mathrm{GL}$, composto fenólico (Duplofen), iodóforo (PVP-I) e solução de álcool etílico a $77^{\circ} \mathrm{GL}$ com $5 \%$ de clorexidina para desinfecção de superficie. Foram analisados quatro pontos em cada equipamento ("carter", pia de lavagem de mãos, encosto de cabeça da cadeira e superficie frontal externa do refletor), utilizando-se a técnica de "spray-wipe-spray". De cada ponto, foram coletadas amostras utilizando-se placas de superficie contendo ágar Mitis Salivarius bacitracina sacarose, ágar Sabouraud Dextrose com cloranfenicol, ágar MacConkey e ágar-sangue para contagem de estreptococos do grupo mutans, leveduras do gênero Candida, bactérias gram-negativas e contagem total de microrganismos, respectivamente (ufc/placa). Os resultados foram analisados estatisticamente utilizando-se teste $t$ de Student para comparação entre as médias de ufc/placa. O desinfetante que demonstrou ser mais efetivo na redução microbiana foi a solução alcoólica de clorexidina, principalmente para bactérias gram-positivas. O iodo e o composto fenólico mostraram ser bastante eficazes na redução microbiana. O álcool etílico a $77^{\circ} \mathrm{GL}$ foi o menos eficaz dos quatro desinfetantes analisados, mas apesar de não ser indicado como desinfetante de superfície, mostrou, no presente trabalho, redução microbiana estatisticamente significativa após o processo de desinfecção.
\end{abstract}

UNITERMOS: Desinfetantes de equipamento odontológico; Infecção.

\begin{abstract}
Surface disinfection is a procedure carried out on the external parts of the dental equipment as well as on other items of the dental office. The aim of this study was to analyze the efficacy of 4 surface disinfectants utilized in dentistry: $77^{\circ} \mathrm{GL}$ alcohol, phenolic compound (Duplofen), iodophor (PVP-I) and $77^{\circ} \mathrm{GL}$ alcohol with $5 \%$ of chlorhexidine. Four surfaces of the equipment were analyzed in the study (the carter, the washbasin for hand-washing, the headrest of the chair and the external surface of the reflector), and the spray-wipe-spray procedure was carried out. From each surface, samples were collected by means of surface plates containing Mitis Salivarius bacitracin sucrose agar, Sabouraud Dextrose agar with chloramphenicol, MacConkey agar and blood agar, for counting mutans streptococci, Candida yeasts, gram-negative bacteria and total microorganisms, respectively (ufc/plate). The results were statistically analyzed by means of the Student's $t$ test in order to compare the mean ufc/plate values. The most effective disinfectant was $77^{\circ} \mathrm{GL}$ alcohol with $5 \%$ of chlorhexidine, mainly against gram-positive bacteria. Iodophor and phenolic compound were also effective in microbial reduction. $77^{\circ} \mathrm{GL}$ alcohol was the least effective product - however, although it is not considered as a surface disinfectant, it produced, in this study, statistically significant microbial reduction after the disinfecting procedure.
\end{abstract}

UNITERMS: Dental disinfectants; Infection.

\section{INTRODUÇÃO}

Prevenir infecção cruzada no consultório odontológico tem sido um grande desafio para cirurgiões-dentistas, pesquisadores e microbiologistas. $\mathrm{Na}$ maior parte das vezes, os microrganismos têm vencido as medidas de segurança adotadas na atualidade, colocando em risco profissionais e pacientes. Por outro lado, a falta de cuidado de alguns profissionais com relação à biossegurança tem propiciado ocorrência de infecção cruzada no consultório odontológico ${ }^{5}$.

Agentes patogênicos podem ser transferidos a partir da cavidade bucal do paciente para as superficies do equipamento odontológico através do contato direto, dedos, instrumentos e respingos de sangue ou saliva ${ }^{2}$.

A contaminação agrava-se nos consultórios pelo uso de equipamentos que produzem aerossóis, através dos quais os microrganismos podem

\footnotetext{
*Professora Assistente de Microbiologia e Imunologia do Departamento de Odontologia da Universidade de Taubaté.

**Professor Adjunto de Microbiologia e Imunologia do Departamento de Biociências da Faculdade de Odontologia de São José dos Campos da Universidade Estadual Paulista e Professor Assistente de Microbiologia e Imunologia do Departamento de Odontologia da Universidade de Taubaté.
} 
Silva CRG, Jorge AOC. Avaliação de desinfetantes de superficie utilizados em Odontologia. Pesqui Odontol Bras 2002; (16)2:107-114.

ser lançados e espalhados até aproximadamente um metro ao redor do campo operatório. Assim, equipamentos odontológicos e acessórios dentro e ao redor da zona operatória podem tornar-se contaminados ${ }^{16}$. O aerossol salivar é considerado um importante veículo nas transmissões de doenças infecciosas em consultórios odontológicos ${ }^{24}$. As mãos do profissional contaminadas pela saliva e sangue também são de fundamental importância no processo de infecção cruzada quando não ocorre, por parte do profissional, uma anti-sepsia minuciosa ao término do atendimento a um paciente e início do atendimento a outro ${ }^{10,11}$.

Todos os indivíduos atendidos no consultório odontológico devem ser considerados como um provável portador de doença infecciosa. Conseqüentemente, o controle das infecções é fundamental e requer, na clínica odontológica, proteção do profissional e do paciente com técnicas de bloqueio mecânico e biológico, esterilização de instrumentais, desinfecção de superficies e equipamentos e a eliminação apropriada de resíduos contaminados $^{12,18,20}$.

Para realização da desinfecção de superfície, vários agentes químicos desinfetantes podem ser utilizados. O passo inicial para o processo de desinfecção incorre no conhecimento de cada um desses produtos, nos seus aspectos principais como: seu mecanismo de ação sobre os microrganismos, toxicidade para o manipulador e ação deletéria para o equipamento a ser desinfetado. A escolha adequada do desinfetante proporciona $\mathrm{o}$ sucesso do processo de desinfecção.

O objetivo do presente trabalho foi verificar a presença de microrganismos na superficie de quatro pontos determinados do equipamento odontológico e analisar a ação de quatro desinfetantes (iodo povidine; álcool etílico a $77^{\circ} \mathrm{GL}$; solução alcoólica com 5\% de clorexidina; composto fenólico) utilizados em clínicas odontológicas, no processo de desinfecção de superficies presentes no consultório.

\section{MATERIAL E MÉTODOS}

Foram coletadas amostras de quatro diferentes pontos da superficie de cinqüenta equipamentos das clinicas do Departamento de Odontologia da Universidade de Taubaté, após os procedimentos de Odontologia Restauradora realizados em pacientes adultos, em que o aparelho de alta rotação foi utilizado pelo tempo mínimo de 5 minutos. Foram utilizados os seguintes pontos para coleta: ponto 1 - "carter" do equipamento odontológico; ponto 2 - encosto de cabeça da cadeira odontológica; ponto 3 - superficie frontal externa do refletor; e ponto 4 - superficie da pia de lavagem de mãos.

As amostras foram coletadas utilizando-se placas de superficie tipo Replicate Organisms Direct Agar Plates (RODAC, Politec) contendo os seguintes meios de cultura: ágar-sangue, ágar Mitis Salivarius bacitracina sacarose, ágar Sabouraud Dextrose com cloranfenicol e ágar MacConkey.

Após os procedimentos odontológicos de rotina, foi efetuada uma limpeza prévia nos quatro pontos selecionados, com gaze esterilizada para a retirada de resíduos e/ou materiais orgânicos, como, saliva, sangue e tecidos. Foi utilizada a técnica borrifar-esponjar-borrifar, na qual borrifou-se a substância a ser testada com spray e, posteriormente, esfregou-se com gaze esterilizada a superficie com movimentos contínuos em um só sentido; borrifou-se novamente o produto realizando a mesma técnica descrita. Após 5 minutos para a secagem e ação do produto utilizado, as placas contendo os meios de cultura foram aplicadas, pressionando-se delicadamente a superficie do ágar no ponto selecionado. O tempo de contato para a coleta foi de 1 minuto.

O procedimento descrito foi realizado para os desinfetantes: iodo povidine com $1 \%$ de iodo ativo (L. M. Farma), álcool etílico a $77^{\circ} \mathrm{GL}$ (Parati 92, $8^{\circ}$ INPM, $\left.96^{\circ} \mathrm{GL}\right)$, solução de álcool etílico a $77^{\circ} \mathrm{GL}$ com $5 \%$ de clorexidina (Manipulário) e composto fenólico (Duplofen).

Como controle, foi efetuada a mesma técnica descrita acima, logo após atendimento do paciente, utilizando-se água destilada esterilizada. A seguir, as placas foram incubadas a $37^{\circ} \mathrm{C}$, os meios de ágar-sangue e ágar Mitis Salivarius bacitracina sacarose foram incubados em estufa com teor de $5 \%$ de $\mathrm{CO}_{2}$. As placas contendo ágar Sabouraud Dextrose foram mantidas à temperatura ambiente por cinco dias. Após incubação, as colônias foram contadas e os resultados expressos em unidades formadoras de colônia por placa (ufc/placa).

Foram selecionadas placas com colônias sugestivas de estafilococos, estreptococos do grupo $\mathrm{mu}$ tans, bacilos gram-negativos e leveduras para o processo de identificação dos microrganismos.

Nas colônias características de estafilococos, foram realizados esfregaços corados pelo método de Gram. Foi obtida cultura pura em caldo infuso de cérebro-coração (BHI, Difco) e a identificação realizada utilizando-se a produção de catalase, semeadura em ágar salgado, produção de coagulase. 
Silva CRG, Jorge AOC. Avaliação de desinfetantes de superfície utilizados em Odontologia. Pesqui Odontol Bras 2002; (16)2:107-114.

$\mathrm{Na}$ interpretação dos resultados, considerou-se presença de estafilococos coagulase-positivo e coagulase-negativo.

Nas colônias sugestivas de estreptococos desenvolvidas no ágar Mitis Salivarius bacitracina sacarose, foi realizada a coloração de Gram e posteriormente culltura pura em caldo BHI para identificação, utilizando-se os testes de fermentação de manitol e sorbitol, hidrólise da esculina, hidrólise da arginina, segundo Jorge ${ }^{8}$ (1997).

Para identificação dos microrganismos gramnegativos provenientes do ágar MacConkey, após obtenção de cultura pura em ágar-nutriente, foram realizadas provas bioquímicas: utilização de citrato, produção de indol, teste de vermelho de metila, teste de Vogues Proskauer, produção de urease, tríplice-açúcar-ferro, motilidade, fenilalanina desaminase e a interpretação dos resultados foi baseada em Holt ${ }^{7}$ (1994).

Para caracterização das amostras de leveduras isoladas que cresceram em ágar Sabouraud Dextrose com cloranfenicol, foram realizadas as provas: formação de tubo germinativo, microcultivo (Corn Meal Ágar, Difco, adicionado de Tween 80), fermentação (zimograma) e assimilação de açúcares (auxanograma). Os resultados foram interpretados, baseando-se em Sandven ${ }^{21}$ (1990).

Foi aplicada, nos resultados obtidos, análise estatística, utilizando-se o teste de $t$ de Student para observar se a redução dos microrganismos pós-desinfecção com os diferentes desinfetantes foi significativa ou não $(\mathrm{p} \leq 0,05)$.

\section{RESULTADOS}

Nos dez equipamentos odontológicos estudados como controle, observou-se crescimento de microrganismos em todos os pontos analisados quando as amostras foram coletadas sem procedi- mento prévio de desinfecção, logo após o término de tratamento odontológico (Tabelas 1 a 5). Na pia de lavagem de mãos, foi observada, através do somatório das médias de ufc/placa nos meios utilizados, maior quantidade de crescimento de microrganismos, mostrando ser o local de maior contaminação dentre os analisados, seguido pelo encosto de cabeça da cadeira. O local onde encon-

TABELA 1 - Microrganismos encontrados nos diferentes locais dos equipamentos odontológicos estudados.

\begin{tabular}{|c|c|c|}
\hline Pontos & $\begin{array}{l}\text { Locais do } \\
\text { equipamento }\end{array}$ & Microrganismos \\
\hline 1 & "Carter" & $\begin{array}{c}\text { Staphylococcus coagulase } \\
\text { negativa } \\
\text { Streptococcus sanguinis } \\
\text { Streptococcus mitior } \\
\text { Enterobacter sakasakii }\end{array}$ \\
\hline 2 & $\begin{array}{c}\text { Encosto de } \\
\text { cabeça }\end{array}$ & $\begin{array}{c}\text { Staphylococcus coagulase } \\
\text { negativa } \\
\text { Streptococcus mitior } \\
\text { Serratia rubideae }\end{array}$ \\
\hline 3 & $\begin{array}{l}\text { Superfície } \\
\text { frontal do } \\
\text { refletor }\end{array}$ & $\begin{array}{c}\text { Estreptococos do grupo mutans } \\
\text { Streptococcus salivarius } \\
\text { Candida albicans } \\
\text { Enterobacter aglomerans }\end{array}$ \\
\hline 4 & $\begin{array}{c}\text { Pia de lavagem } \\
\text { de mãos }\end{array}$ & $\begin{array}{c}\text { Staphylococcus coagulase } \\
\text { negativa } \\
\text { Streptococcus sanguinis } \\
\text { Candida parapsilosis } \\
\text { Candida guilliermondii } \\
\text { Candida albicans }\end{array}$ \\
\hline
\end{tabular}

TABELA 2 - Médias e desvio padrão de ufc/placa encontrados na superfície do "carter" do equipamento odontológico, nos meios de cultura utilizados antes e após desinfecção com diferentes desinfetantes.

\begin{tabular}{|c|c|c|c|c|}
\hline Desinfetantes & $\begin{array}{c}\text { Ágar-sangue } \\
n=50\end{array}$ & $\begin{array}{c}\text { Ágar MSBS } \\
n=50\end{array}$ & $\begin{array}{c}\text { Ágar MacConkey } \\
n=50\end{array}$ & $\begin{array}{c}\text { Ágar Sabouraud } \\
n=50\end{array}$ \\
\hline Controle & $58,85 \pm 106,18$ & $3,85 \pm 5,28$ & $0,55 \pm 1,19$ & $1,5 \pm 2,37$ \\
\hline Iodo povidine & $0,1 \pm 0,31$ & \pm 0 & \pm 0 & $0 \pm 0$ \\
\hline Álcool etílico a $77^{\circ} \mathrm{GL}$ & $0,7 \pm 1,06$ & \pm 0 & \pm 0 & $0 \pm 0$ \\
\hline Clorexidina & $0,7 \pm 2,21$ & \pm 0 & \pm 0 & $0,1 \pm 0,31$ \\
\hline Composto fenólico & $0,9 \pm 1,60$ & $0,1 \pm 0,31$ & $0 \pm 0$ & $0,1 \pm 0,31$ \\
\hline
\end{tabular}

MSBS = Mitis Salivarius bacitracina sacarose. 
Silva CRG, Jorge AOC. Avaliação de desinfetantes de superficie utilizados em Odontologia. Pesqui Odontol Bras 2002; (16)2:107-114.

TABELA 3 - Médias e desvio padrão de ufc/placa encontrados na superfície do encosto de cabeça do equipamento odontológico, nos meios de cultura utilizados antes e após desinfecção com diferentes desinfetantes.

\begin{tabular}{|c|c|c|c|c|}
\hline Desinfetantes & $\begin{array}{c}\text { Ágar-sangue } \\
n=50\end{array}$ & $\begin{array}{c}\text { Ágar MSBS } \\
n=50\end{array}$ & $\begin{array}{c}\text { Ágar MacConkey } \\
n=50\end{array}$ & $\begin{array}{c}\text { Ágar Sabouraud } \\
\mathrm{n}=50\end{array}$ \\
\hline Controle & $65,6 \pm 69,09$ & $9,75 \pm 7,14$ & $0,35 \pm 0,49$ & $3,0 \pm 5,60$ \\
\hline Iodo povidine & $2,9 \pm 6,17$ & $0,2 \pm 0,42$ & $0 \pm 0$ & $0 \pm 0$ \\
\hline Álcool etílico a $77^{\circ} \mathrm{GL}$ & $3,3 \pm 2,91$ & $0,2 \pm 0,63$ & \pm 0 & $0 \quad \pm 0$ \\
\hline Clorexidina & $0,8 \pm 1,03$ & $0 \pm 0$ & \pm 0 & $0,1 \pm 0,31$ \\
\hline Composto fenólico & $1,5 \pm 1,24$ & $0,1 \pm 0,31$ & \pm 0 & $0,2 \pm 0,42$ \\
\hline
\end{tabular}

MSBS = Mitis Salivarius bacitracina sacarose.

TABELA 4 - Médias e desvio padrão de ufc/placa encontrados na superficie frontal do refletor do equipamento odontológico, nos meios de cultura utilizados antes e após desinfecção com diferentes desinfetantes.

\begin{tabular}{|c|c|c|c|c|}
\hline Desinfetantes & $\begin{array}{c}\text { Ágar-sangue } \\
\mathrm{n}=50\end{array}$ & $\begin{array}{c}\text { Ágar MSBS } \\
\mathrm{n}=50\end{array}$ & $\begin{array}{c}\text { Ágar MacConkey } \\
n=50\end{array}$ & $\begin{array}{c}\text { Ágar Sabouraud } \\
n=50\end{array}$ \\
\hline Controle & $14,5 \pm 17,23$ & $4,0 \pm 8,19$ & $0,15 \pm 0,37$ & $1,2 \pm 1,54$ \\
\hline Iodo povidine & $1,2 \pm 1,62$ & $0 \pm 0$ & $0 \pm 0$ & $0 \pm 0$ \\
\hline Álcool etílico a $77^{\circ} \mathrm{GL}$ & $1,3 \pm 1,63$ & $0 \pm 0$ & $0,1 \pm 0,31$ & $0 \pm 0$ \\
\hline Clorexidina & $0,4 \pm 1,26$ & $0 \pm 0$ & $0 \pm 0$ & $0 \pm 0$ \\
\hline Composto fenólico & $0,5 \pm 0,53$ & $0,6 \pm 1,27$ & $0 \pm 0$ & $0 \pm 0$ \\
\hline
\end{tabular}

MSBS = Mitis Salivarius bacitracina sacarose.

trou-se menor contaminação foi a superfície frontal do refletor do equipamento (Tabela 6).

A maior prevalência de microrganismos nos pontos analisados foi de estreptococos bucais, seguido por Staphylococcus coagulase negativos, e leveduras do gênero Candida. Observou-se também, porém, em menor quantidade, nos pontos 1 , 2 e 3 presença de bacilos gram-negativos (Tabelas 1 a 5).

Após processo de desinfecção com os desinfetantes selecionados, observou-se redução estatisticamente significativa $(\mathrm{p} \leq 0,05)$ para o álcool etílico a $77^{\circ} \mathrm{GL}$, iodo povidine, clorexidina e composto fenólico nos pontos 1,2 e 4 . No ponto 3, verificou-se redução não significativa para microrganismos gram-negativos. Para o desinfetante à base de composto fenólico, não houve também redução estatisticamente significativa no ponto 3 para os estreptococos bucais (Tabelas 2 a 5).

A atividade de cada desinfetante frente aos diferentes tipos de microrganismos encontrados pôde ser observada após comparação entre as médias de ufc/placa em equipos não desinfetados e em equipos desinfetados. O desinfetante mais efetivo contra bactérias gram-positivas foi a clorexidina (média de ufc/placa de 2,3), seguida pelo composto fenólico (média de ufc/placa de 4,6), iodo povidine (média de ufc/placa de 7,3) e álcool etílico a $77^{\circ} \mathrm{GL}$ (média de ufc/placa de 12,4) (Tabela 6).

$\mathrm{O}$ iodo povidine foi o desinfetante que apresentou maior efetividade para leveduras do gênero Candida, seguido por álcool etílico a $77^{\circ} \mathrm{GL}$, clorexidina e composto fenólico. Para bactérias gramnegativas, verificou-se eficácia no processo de desinfecção para todos os desinfetantes analisados. Observou-se que, para a redução de estreptococos do grupo mutans, o desinfetante clorexidina foi o mais eficiente, seguido pelo álcool etílico a $77^{\circ} \mathrm{GL}$, iodo povidine e composto fenólico.

\section{DISCUSSÃO}

Nas superficies dos equipamentos odontológicos analisadas neste estudo, observou-se presença de grandes quantidades de microrganismos, com somatório das médias de ufc/placa de 286,75 (Tabela 6). Esses microrganismos foram possivelmente lançados pela utilização de instrumentos geradores de aerossol bucal. Esses aparelhos lan- 
Silva CRG, Jorge AOC. Avaliação de desinfetantes de superfície utilizados em Odontologia. Pesqui Odontol Bras 2002; (16)2:107-114

TABELA 5 - Médias e desvio padrão de ufc/placa encontrados na superficie da pia de lavagem de mãos do equipamento odontológico, nos meios de cultura utilizados, antes e após desinfecção com diferentes desinfetantes.

\begin{tabular}{l|c|c|c|c}
\hline \hline \multicolumn{1}{c|}{ Desinfetantes } & $\begin{array}{c}\text { Ágar-sangue } \\
\mathrm{n}=50\end{array}$ & $\begin{array}{c}\text { Ágar MSBS } \\
\mathrm{n}=50\end{array}$ & $\begin{array}{c}\text { Ágar MacConkey } \\
\mathrm{n}=50\end{array}$ & $\begin{array}{c}\text { Ágar Sabouraud } \\
\mathrm{n}=50\end{array}$ \\
\hline Controle & $106,15 \pm 127,54$ & $14,15 \pm 23,38$ & $0,6 \pm 0,82$ & $2,5 \pm 4,38$ \\
\hline Iodo povidine & $2,8 \pm 3,39$ & $0,1 \pm 0,31$ & $0 \pm 0$ & $0 \pm 0$ \\
\hline Álcool etílico a 77 $\mathrm{GL}$ & $6,8 \pm 15,48$ & $0 \pm 0$ & $0 \pm 0$ & $0,1 \pm 0,31$ \\
\hline Clorexidina & $0,2 \pm 0,42$ & $0 \pm 0$ & $0 \pm 0$ & $0 \pm 0$ \\
\hline Composto fenólico & $0,9 \pm 0,88$ & $0,1 \pm 0,31$ & $0 \pm 0$ & $0,3 \pm 0,48$ \\
\hline \hline
\end{tabular}

MSBS = Mitis Salivarius bacitracina sacarose.

TABELA 6 - Somatório das médias de ufc/placa do grupo controle e dos grupos de desinfetantes estudados em todos os meios de cultura utilizados, de acordo com cada ponto de coleta.

\begin{tabular}{l|c|c|c|c|c}
\hline \hline \multirow{2}{*}{ Pontos de coleta } & \multicolumn{5}{|c}{ Somatório das médias de ufc/placa } \\
\cline { 2 - 6 } "Carter" & Controle & Álcool etílico a 77 ${ }^{\circ} \mathrm{GL}$ & Iodo povidine & Clorexidina & Composto fenólico \\
\hline Encosto de cabeça & 64,75 & 0,7 & 0,1 & 0,8 & 1,1 \\
\hline $\begin{array}{l}\text { Superfície frontal do } \\
\text { refletor }\end{array}$ & 78,75 & 3,5 & 3,1 & 0,9 & 1,1 \\
\hline $\begin{array}{l}\text { Pia de lavagem de } \\
\text { mãos }\end{array}$ & 123,85 & 1,4 & 1,2 & 0,4 & 1,1 \\
\hline Total & 286,75 & 6,8 & 2,9 & 0,2 & 1,3 \\
\hline \hline
\end{tabular}

çam, até aproximadamente um metro ao redor da área operatória, aerossol salivar repleto de microrganismos provenientes da cavidade bucal. As mãos contaminadas do profissional em contato com diversas superficies também contribuem para espalhar microrganismos, proporcionando o aumento do risco no processo de transmissão desses microrganismos entre pacientes e entre os membros da equipe odontológica ${ }^{3,15,16,24}$.

Dentre os microrganismos encontrados, observou-se maior prevalência de estreptococos bucais, presentes em todas as superficies analisadas (Tabela 1), totalizando uma média de $7,8 \mathrm{ufc} /$ placa. As amostras foram coletadas sem procedimentos de desinfecção e após procedimentos de rotina. Os resultados do presente trabalho concordam com os de Noro et al. ${ }^{16}$ (1998) que, estudando contaminação do ambiente odontológico, observaram que a maior quantidade de microrganismos presentes foi de estreptococos alfa-hemoliticos (em torno de $75 \%)$. Hackney Jr. et al. ${ }^{6}$ (1998) também demonstraram em 45 amostras coletadas de superficies limpas do consultório antes do tratamento dentá- rio, a presença de estreptococos alfa-hemolíticos em $7 \%$ das coletas. Entretanto, em uma nova coleta após tratamento dentário, 54\% delas mostraram-se positivas para estreptococos alfa-hemolíticos, indicando que esse microrganismo é encontrado em superfícies do consultório dentário em grande quantidade podendo ser usado como indicador de contaminação ambiental.

Outro microrganismo encontrado foi Staphylococcus coagulase negativo, estando presente em três das quatro superficies analisadas (Tabela 1). Signoreto et al. ${ }^{24}$ (1994) relataram que estafilococos, ao contrário de estreptococos bucais, são utilizados como indicador da presença humana, pelo fato de os mesmos geralmente colonizarem toda a superficie de seres humanos. Os autores observaram a presença desse microrganismo em cargas variáveis em todos os locais estudados.

Leveduras do gênero Candida também foram encontradas nos nossos resultados, em alguns equipamentos na superficie frontal do refletor e pia de lavagens de mãos, totalizando uma média de 2,05 ufc/placa. Nesta última superficie citada, fo- 
Silva CRG, Jorge AOC. Avaliação de desinfetantes de superficie utilizados em Odontologia. Pesqui Odontol Bras 2002; (16)2:107-114.

ram encontradas Candida albicans, Candida guilliermondii e Candida parapsilosis, provavelmente porque a umidade presente neste local favoreceu o crescimento e a sobrevivência desses microrganismos. A presença de leveduras do gênero Candida na cavidade bucal, fazendo parte da microbiota comensal dessa região, tem sido extensivamente comprovada por pesquisadores que reportam a sua presença em indivíduos normais em torno de $20 \%$ a $50 \%$, sendo a Candida albicans a espécie mais comum do gênero ${ }^{10,17,28}$.

Observamos também menor quantidade de microrganismos gram-negativos, totalizando uma média de 0,4 ufc/placa, estando presente em três superficies das quatro estudadas. Foram identificadas duas espécies do gênero Enterobacter e uma do gênero Serratia; achados similares a resultados encontrados em estudos feitos por Sedgley, Samaranayake $^{23}$ (1994), em que observaram que, dentre todos os bacilos gram-negativos encontrados em seus resultados, $73 \%$ eram pertencentes ao gênero Enterobacter. Esses microrganismos não são considerados residentes da microbiota da cavidade bucal, fazendo parte entretanto da microbiota normal do intestino de indivíduos normais ${ }^{7}$. Por esse motivo, é reportado por vários autores que, mesmo uma pequena quantidade desses microrganismos em locais fora do seu habitat natural, pode indicar contaminação fecal, principalmente por higenização e limpeza inadequada.

Após processos de desinfecção nas superficies analisadas, observamos que todos os desinfetantes testados mostraram redução significativa na maioria dos microrganismos encontrados. O desinfetante a base de iodo (iodóforo-PVPI) demonstrou ação eficaz contra todos os microrganismos, apresentando redução estatisticamente significativa. Os desinfetantes a base de iodo são aprovados pela Agência de Proteção Ambiental (APA) como desinfetantes hospitalares, de nivel intermediário de desinfecção, sendo tuberculocidas e viricidas com ação em vírus lipofilicos e hidrofilicos, tendo uma ação limpante e desinfetante ${ }^{1,25,27}$.

Existe vasta literatura mostrando a ineficiência do álcool etílico como desinfetante de superficie, inclusive não sendo aprovado pelo Centro de Controle de Doenças e Prevenção (CDC) e Agência de Proteção Ambiental (APA) para esse fim. A ineficiência relatada é decorrente da propriedade do álcool em precipitar proteinas teciduais que normalmente estão presentes no sangue e na saliva, e podem ser carreadas pelo aerossol salivar ou mãos contaminadas de profissionais, depositan- do-se nas superficies. Outro fator discutido com relação à ineficiência do álcool etílico como desinfetante de superficie é sua rápida evaporação, limitando a sua atividade sobre vírus e bactérias com cobertura protéica ${ }^{4,9,13,14,20,22}$.

Entretanto, na ausência de exsudatos purulentos repletos de proteínas, o álcool é ativo contra vírus lipofilicos, é bactericida, fungicida e tuberculo$\mathrm{cida}^{22}$. Sua caracteristica de solubilizar lipídios acentua sua ação, sendo efetivo sobre envelopes de vírus. É também utilizado como solvente em outros desinfetantes no intuito de lhes conferir melhores propriedades ${ }^{27}$.

Quando comparamos a ação do álcool etílico a $77^{\circ} \mathrm{GL}$ na desinfecção de superficies, observamos que ele foi o menos eficiente, totalizando uma média de 12,4 ufc/placa (Tabela 6). Entretanto, observamos que o processo de redução microbiana após a sua utilização foi estatisticamente significante para todos os locais desinfetados.

$\mathrm{Na}$ redução de microrganismos no "carter" do equipamento (Tabela 2), o desinfetante mais efetivo foi o iodo povidine, seguido pelo álcool etílico. A ação do álcool nessa superfície foi mais eficaz que o desinfetante clorexidina e o desinfetante à base de composto fenólico. Essa ação provavelmente é decorrente de procedimentos preestabelecidos nas clínicas do Departamento de Odontologia da Universidade de Taubaté, onde se preconiza a utilização de pano de campo esterilizado sobre a superficie do "carter". Essa proteção deve barrar ou diminuir a concentração de proteínas da saliva ou do sangue, proporcionando assim uma ação mais eficaz do álcool na ausência ou baixa concentração dessas proteinas.

Van Bueren et al. ${ }^{26}$ (1994) demonstraram a inativação do vírus HIV $\left(10^{4}\right.$ unidades de infecção $\left./ \mathrm{ml}\right)$ pelo álcool etílico a 70\% em culturas líquidas independentemente da quantidade de proteínas existentes no meio. Entretanto, essa atividade foi diminuída quando se testaram vírus secos sobre superficies, devido à rápida evaporação e, provavelmente, pela precipitação de proteínas.

Observou-se redução estatisticamente significativa, apesar de o álcool etílico não ser o melhor desinfetante testado. Esses resultados levam-nos a sugerir que, se for efetuado um processo de limpeza adequado, com fricção vigorosa da superfície a ser desinfetada para a remoção de proteínas do sangue ou saliva, o álcool etílico a $77^{\circ} \mathrm{GL}$ pode ser utilizado, apesar de não ser recomendado para desinfecção de superfície.

O desinfetante à base de composto fenólico utilizado (Duplofen) mostrou eficiência na redução 
Silva CRG, Jorge AOC. Avaliação de desinfetantes de superfície utilizados em Odontologia. Pesqui Odontol Bras 2002; (16)2:107-114.

microbiana das superficies analisadas, sendo classificado, dentre os desinfetantes testados, como o segundo melhor no que se refere aos microrganismos encontrados, totalizando uma média de 4,6 ufc/placa (Tabela 6). Esse resultado já era esperado, pois esse desinfetante foi aprovado pelo APA e pelo CDC como desinfetante de superficie, sendo ao mesmo tempo um agente limpante e desinfetante que mantém sua atividade e efetividade em presença de compostos orgânicos. Também são eficazes em presença de detergentes, mostrando resultados excelentes para desinfecção de superficies ${ }^{4}$.

Solução a 5\% de clorexidina em álcool etílico a $77^{\circ} \mathrm{GL}$ foi o desinfetante que proporcionou maior redução microbiana, totalizando uma média de 2,3 ufc/placa (Tabela 6). Samaranayake ${ }^{19}$ (1993) reporta que solução alcoólica de gluconato de clorexidina é amplamente utilizada como desinfetante de superfície em diversos países, com exceção dos Estados Unidos.

Os dados ora obtidos concordam com estudos feitos por Signoretto et al. ${ }^{24}$ (1994), em que a clorexidina foi mais eficaz na redução microbiana do ambiente, diminuindo de 1 a 30 minutos, a população de microrganismos em $90 \%$. Para S. mutans e $S$. salivarius a redução obtida foi de $99,9 \%$ em 15 minutos.

O uso de desinfetantes de superficie é uma das muitas enfatizadas e confusas áreas de controle de infecção na Odontologia ${ }^{4}$. Tendo em vista este enfoque, o profissional da área de Saúde necessita estar consciente do que é um desinfetante ideal, para qual finalidade será utilizado, qual a popula-

\section{REFERÊNCIAS}

1. American Dental Association. Council on Scientific Affairs. Council on Dental Practice. Infection control recommendations for the dental office and the laboratory. J Am Dent Assoc 1996;127:672-80.

2. Autio KL, Rosen S, Reynolds NJ, Bright JS. Studies on cross-contamination in the dental clinic. J Am Dent Assoc 1980;100:358-61.

3. Cannata S, Bek M, Baker RP, Fett M. Infection control and contaminated waste disposal practices in southern Sydney area health service dental clinics. Aust Dent J 1997;42:199-202.

4. Cottone JA, Molinari JA. State-of-the-art: infection control in dentistry. J Am Dent Assoc 1991;123:33-41.

5. Ferreira RA. Barrando o invisível. Rev Assoc Paul Cir Dent 1995;49:417-27.

6. Hackney Junior J, Crawford JJ, Tulis JJ. Using a biological indicator to detect potential sources of cross-contamination in the dental operatory. J Am Dent Assoc 1998; 129:1567-77. ção microbiana que deseja atingir, quais as vantagens e desvantagens do produto, e por meio desses conhecimentos, escolher o desinfetante a ser utilizado levando em conta o risco, custo e benefícios.

\section{CONCLUSÕES}

Com base na análise dos resultados obtidos no presente trabalho podemos concluir que:

1. as superficies do equipamento odontológico estão contaminadas após atendimento odontológico, representando riscos de transmissão de infecção cruzada;

2. os microrganismos encontrados em maior concentração em praticamente todas as superficies analisadas foram Streptococcus alfa-hemolitico, os quais podem ser utilizados como indicadores de contaminação bucal do ambiente; evidenciou-se presença de bactérias gram-negativas em pequenas quantidades nas superficies estudadas, o que denota provável má higienização e limpeza de alguns equipamentos;

3. o desinfetante mais efetivo foi a solução alcoólica de clorexidina, com ação bastante eficaz na redução de microrganismos, principalmente para bactérias gram-positivas. O iodo foi bastante efetivo principalmente para leveduras do gênero Candida. O composto fenólico também mostrou efetividade na redução de microrganismos e o álcool etílico a $77^{\circ} \mathrm{GL}$ foi o menos eficaz dos desinfetantes testados, entretanto mostrando uma redução estatisticamente significativa de microrganismos.

7. Holt JG, Krieg NR, Sneath PHA, Staley JT, Williams ST. Bergey's manual of determinative bacteriology. 9. ed. Baltimore : Williams \& Wilkins, 1994.

8. Jorge AOC. Microbiologia: atividades práticas. São Paulo : Santos, 1997.

9. Jorge AOC. Princípios de biossegurança em Odontologia. Departamento de Odontologia. Universidade de Taubaté. 1998.

10. Jorge AOC, Koga-Ito CY, Gonçalves CR, Fantinato V, Unterkircher CS. Presença de leveduras do gênero Candida na saliva e pacientes com diferentes fatores predisponentes e de indivíduos controle. Rev Odontol Univ São Paulo 1997;11:279-85.

11. Miller $\mathrm{CH}$. Cleaning, sterilization and disinfection: basics of microbial killing for infection control. J Am Dent Assoc 1993; $124: 48-56$.

12. Miller $\mathrm{CH}$. Infection control. Dent Clin North Am 1996;40:437-56.

13. Molinari JA. Controversies in infection control. Dent Clin North Am 1990;34:55-69. 
Silva CRG, Jorge AOC. Avaliação de desinfetantes de superficie utilizados em Odontologia. Pesqui Odontol Bras 2002; (16)2:107-114.

14. Molinari JA. Dental infection control forum: use and misuse of disinfectants. Compendium Contin Educ Dent 1995; 16:538-42.

15. Noro A, Yanaka N, Takahashi K, Ishikawa T, Ogino J, Takahashi E, Suyama Y. A study on prevention of hospital infection control caused by tooth preparation dust in the dental clinic. Bull Tokyo Dent Coll 1995;36:201-6.

16. Noro A, Suyama Y, Takahashi E, Chattin BR, Hirai Y, Takahashi $\mathrm{K}$, Ishikawa $\mathrm{T}$. The effectiveness of the "clean-area-system" for infection control in the dental clinic. Bull Tokyo Dent Coll 1998;39:15-24.

17. Rindum JL, Stenderup A, Homstrup P. Identification of Candida albicans types related to healthy and pathological oral mucosa. J Oral Pathol Med 1994;23:406-12.

18. Runnells RR. Clínicas de Odontologia da América do Norte: controle da infecção e segurança no consultório. Rio de Janeiro : Interlivros, 1991.

19. Samaranayake LP. Rules of infection control. Int Dent $J$ 1993;43:578-84.

20. Samaranayake LP, Scheutz F, Cottone JA. Controle da infecção para equipe odontológica. São Paulo : Santos, 1993.

21. Sandven P. Laboratory identification and sensitivity testing of yeast isolates. Acta Odontol Scand 1990;48:27-36.
22. Secretaria do Estado da Saúde de São Paulo. Centro de Apoio ao Desenvolvimento de Assistência Integral à Saúde - CADAIS. Organização do centro de materiais e noções de esterilização. São Paulo, 1993. 65 p. (Cadernos de Saúde).

23. Sedgley CM, Samaranayake LP. The oral prevalence of aerobic and facultatively anaerobic gram-negative rods and yeasts in Hong Kong Chineses. Arch Oral Biol 1994;39:459-66.

24. Signoretto C, Canepari P, Urbani G. L'inquinament microbiologico nell' ambulatorio odontoiatrico ed il suo possibile abbattimento. Min Stomatol 1994;43:263-72.

25. Terezhalmy GT, Gitto CA. Today's minimal requirements for a practical dental office infection control and exposure control program. Dent Clin North Am 1998;42:629-42.

26. Van Buerem JV, Larkin DP, Simpson RA. Inativation of human immunodeficiency virus type 1 by alcohols. J Hosp Infec 1994;28:137-48.

27. Verhagen C. Environmental surface disinfectants. J Michigan Dent Assoc 1998;80:2-6.

28. Willians DW, Potts AJ, Wilson MJ, Mathews JB, Lewis MA. Characterization of the inflammatory cell infiltrate in chronic hyperplastic candidosis of the oral mucosa. Oral Pathol Med 1997;26:83-9.
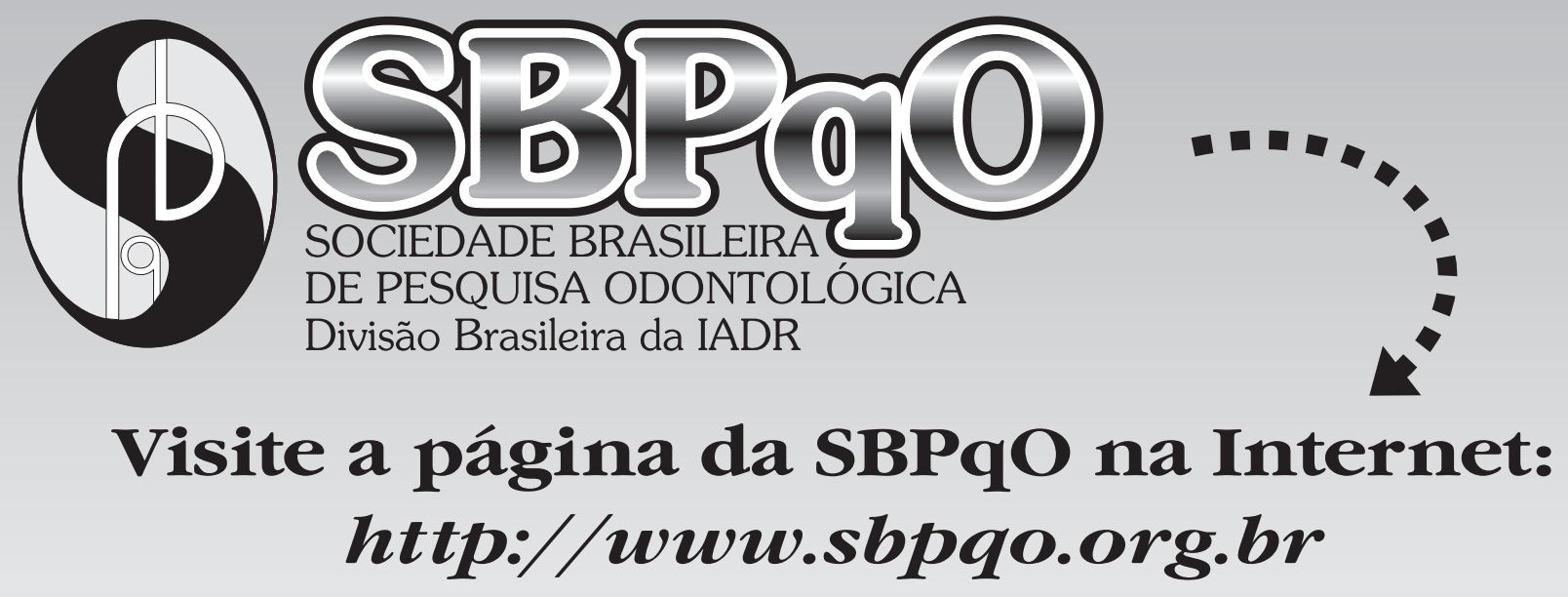

SBPqO - Av. Professor Lineu Prestes, 2.227

CEP 05508-900 - Cidade Universitária - São Paulo - SP Tel./Fax: 0**11-3091-7855 - E-mail: sbpqo@sbpqo.org.br 